\title{
Seleção de progênies do cruzamento entre cultivares de cafeeiros Icatu e Catuaí ${ }^{1}$
}

\author{
Cristiano de Andrade Gomes*2, Gladyston Rodrigues Carvalho ${ }^{3}$, César Elias Botelho ${ }^{3}$, \\ André Dominghetti Ferreira ${ }^{4}$, Juliana Costa Rezende ${ }^{3}$, Ramiro Machado Rezende ${ }^{5}$
}

http://dx.doi.org/10.1590/0034-737X201562010008

\section{RESUMO}

Os programas de melhoramento devem ser dinâmicos e contínuos, de modo a disponibilizarem sempre novos cultivares de cafeeiros, com fatores de resistência complexos, que se constituam em eficientes barreiras para as novas raças fisiológicas do fungo $H$. vastatrix. Por essa razão, objetivou-se, com este trabalho, avaliar o comportamento agronômico, a resistência à ferrugem e a ocorrência de cercosporiose em progênies, provenientes do cruzamento dos grupos de cultivares Catuaí e Icatu, em dois ambientes de Minas Gerais. Os experimentos foram implantados nas Fazendas Experimentais da EPAMIG, em São Sebastião do Paraíso e Três Pontas - MG. O delineamento experimental adotado foi o látice quadrado 6 x 6, com 3 repetições. Nos dois ambientes, foram realizadas avaliações de produtividade, vigor vegetativo, percentagem de grãos com peneira 17 acima e reação à ferrugem e à cercosporiose, nos anos agrícolas 2009/2010 e 2010/2011. O desempenho das progênies avaliadas, para produtividade, em Três Pontas, foi superior quando comparado ao de São Sebastião do Paraíso. A progênie H 6-47-10 Cova 3 destacou-se entre as mais promissoras, sugerindo boas possibilidades de progresso genético na seleção.

Palavras-chave: Coffea arabica L., melhoramento genético, produtividade, ferrugem, cercosporiose.

\section{ABSTRACT}

\section{Selection of progeny from the cross between Icatu and Catuai cultivars}

Breeding programs should be dynamic and continuous in order to provide new coffee cultivars with complex resistance factors to be efficient barriers to new physiological races of the fungus $H$. vastatrix. In this context, the objective of this work was to evaluate the agronomic performance, the resistance to rust and the occurrence of brown eyespot in progenies derived from crosses between Catuaí and Icatu groups in two sites in the State of Minas Gerais. The experiments were carried out on EPAMIG Experimental Farms situated in São Sebastião do Paraíso and Três Pontas, State of Minas Gerais, Brazil. The experimental design was a 6 x 6 lattice square with three replications. The following characteristics were evaluated in the 2009/2010 and 2010/2011crop years in both sites: yield, vegetative vigor, percentage of grain size and response to rust and brown eyespot. Performance of the evaluated progenies for productivity in Três Pontas was higher than in São Sebastião do Paraíso. The progeny 6-47-10 H Hole 3 stood out among the most promising, suggesting good potential for genetic progress in selection. Progenies with resistance to rust were classified.

Key words: Coffea arabica L., breeding, brown eyespot, coffee, rust, yield.

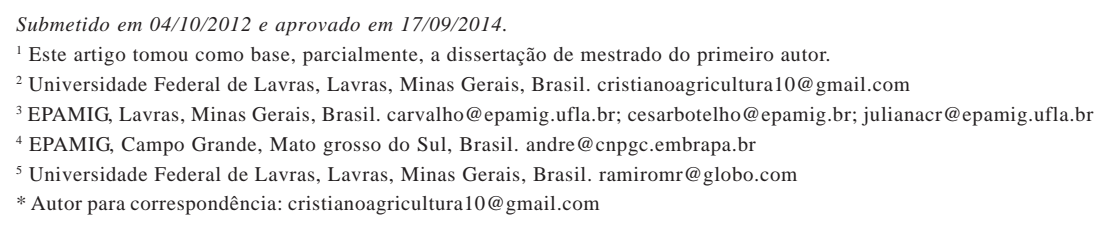




\section{INTRODUÇÃO}

Dentre os fatores limitantes ao processo de produção do café arábica, destaca-se a ferrugem alaranjada do cafeeiro, principal doença dessa espécie, no mundo, que provoca desfolha, resultando em menor vingamento da florada e dos frutos, além de morte dos ramos plagiotrópicos, podendo comprometer a produtividade da lavoura em mais de 50\% (Garçon et al., 2004).

A importância econômica da doença, portanto, é o maior estímulo à utilização de cultivares resistentes, para se evitar, ou, pelo menos, minimizar, os prejuízos por ela ocasionados. Além das vantagens de ordem econômica, o plantio de cafeeiros resistentes à ferrugem proporciona a redução do risco de contaminação ambiental, principalmente pela redução da necessidade de agrotóxicos, bem como a dos trabalhadores envolvidos, sobretudo no processo de aplicação desses produtos.

Por essas razões, há uma concentração de esforços no desenvolvimento e manutenção de cultivares de café resistentes a essa doença (Costa et al., 2007; Petek et al., 2007; Sera et al., 2007). Dentro do germoplasma de café existe boa variabilidade para resistência à ferrugem, cuja utilização em programas de melhoramento genético com essa finalidade, já proporcionou condições para a obtenção e utilização comercial de diversos cultivares portadores de resistência, dispensando total, ou parcialmente, o uso de fungicidas.

Uma importante fonte de resistência à ferrugem alaranjada do cafeeiro são os cultivares do Grupo Icatu, obtidos a partir de hibridação interespecífica realizada pelo Instituto Agronômico de Campinas, entre um cafeeiro tetraploide de $C$. canephora e uma planta do cultivar Bourbon de C. arabica. Dentro deste grupo, há cultivares com resistência específica e outros com resistência não específica. A resistência não específica confere à planta a capacidade de reduzir a penetração, o estabelecimento ou a colonização deste patógeno nos tecidos da folha, atuando em um ou mais estádios do ciclo da doença (Hooker, 1967), enquanto a resistência específica é, usualmente, controlada por um ou poucos genes, sendo, portanto efêmera, em virtude da evolução da virulência do fungo. Os cultivares deste grupo são caracterizados pelo elevado vigor vegetativo e variabilidade quanto à resistência às pragas e doenças. Apresentam, ainda, rusticidade e elevados índices de produtividade (Correa et al. 2006; Carvalho et al., 2009).

Outro genótipo com boas características a serem aproveitadas em um programa de melhoramento genético é o do Grupo Catuaí. Oriundo de hibridações entre progênies de Caturra Amarelo e Mundo Novo, o grupo é caracterizado por plantas que apresentam internódios curtos, frutos de coloração amarela ou vermelha e maturação média, porte baixo, susceptibilidade à ferrugem e boa capacidade produtiva, estabilidade e adaptabilidade fenotípica (Botelho et al. 2010a).

Contudo, o contínuo aparecimento de novas raças fisiológicas com maior número de genes de virulência tem ocasionado a quebra de resistência de inúmeros cultivares (Sera et al., 2010). Por isso, os programas de melhoramento devem ser dinâmicos e contínuos, de modo a disponibilizar sempre novos cultivares com fatores de resistência complexos, que se constituam em eficientes barreiras para as novas raças fisiológicas do fungo H. vastatrix. Berk \& Broome.

Outra doença de importância econômica para a cultura é a cercosporiose, também conhecida como mancha-de-olho-pardo, causada por Cercospora coffeicola Berk. \& Cooke. O patógeno causa lesões, em folhas, que resultam em desfolha, e lesões em frutos, que prejudicam a qualidade da bebida. Ainda não foi observada resistência completa à cercosporiose, em cultivares de cafeeiro, supondo-se que se trata de uma resistência quantitativa (Dell' Acqua et al., 2011).

Por estas razões, objetivou-se avaliar, neste trabalho, o comportamento agronômico, a resistência à ferrugem e a ocorrência de cercosporiose de progênies oriundas do cruzamento de cafeeiros dos grupos Catuaí e Icatu, em dois ambientes de Minas Gerais.

\section{MATERIAL E MÉTODOS}

Os experimentos foram conduzidos nas Fazendas Experimentais da Empresa de Pesquisa Agropecuária de Minas Gerais (EPAMIG), em São Sebastião do Paraíso (FESP) e em Três Pontas (FETP), ambas na região sul de Minas Gerais. A FESP situa-se a $20^{\circ} 54^{\prime} 59^{\prime \prime} \mathrm{S}$ e $47^{\circ}$ 06' 57" W, em altitude de $840 \mathrm{~m}$; apresenta temperatura média de $21,7^{\circ} \mathrm{C}$, precipitação anual média de $1650 \mathrm{~mm}$, em área de relevo plano e solo do tipo Latossolo Vermelho distrófico com textura argilosa. A FETP situa-se a $21^{\circ} 00^{\prime} 22^{\prime \prime} \mathrm{S}$ e $45^{\circ} 30^{\prime} 45^{\prime \prime} \mathrm{W}$, em altitude de $900 \mathrm{~m}$; apresenta temperatura média de $20,1^{\circ} \mathrm{C}$, com precipitação média anual de 1670 mm, em um Latossolo Vermelho distrófico, de textura argilosa e relevo ondulado. Os atributos químicos de cada solo são apresentados na Tabela 1 .

Foram avaliadas 33 progênies, resultantes de uma população segregante, oriunda do cruzamento natural entre os cultivares Icatu e Catuaí. As sementes dessas progênies foram levadas à Fazenda Terra Roxa, município de Santo Antônio do Amparo, por pesquisadores do extinto IBC (Instituto Brasileiro do Café), atualmente vinculados à Fundação Procafé e MAPA (Ministério da Agricultura, Pecuária e Abastecimento). Dessa população, foram selecionadas plantas superiores e novos experi- 
mentos foram instalados nas Fazendas Experimentais da EPAMIG e na UFLA, sendo então geradas sucessivas gerações, até chegar à atual $\left(\mathrm{F}_{6}\right)$. A fonte utilizada para obtenção de resistência à ferrugem nas progênies foram os cultivares do grupo Icatu. Como testemunhas foram utilizados os cultivares Catuaí Amarelo IAC 62, susceptível à ferrugem, e os cultivares Catucaí Amarelo 2SL e Icatu Precoce IAC 3282, usados como padrão de resistência.

Os experimentos foram instalados em janeiro de 2007, em espaçamento de 3,50 m entre linhas x 0,80 m entre plantas, sendo a condução das lavouras realizada de acordo com as recomendações técnicas para a cultura do cafeeiro (Reis \& Cunha, 2010). Não foram realizados os controles de ferrugem e de cercosporiose, visando a avaliar o comportamento das progênies quanto à reação às duas doenças.

O delineamento adotado foi o de blocos incompletos (látice) quadrado 6 x 6, com 3 repetições. As parcelas foram constituídas por dez plantas, sendo consideradas úteis apenas as seis plantas centrais. Nos dois ambientes, foram feitas avaliações de produtividade, vigor vegetativo, percentagem de grãos com peneira 17 e acima e cercosporiose, nos anos agrícolas 2009/2010 e 2010/2011. A incidência da ferrugem do cafeeiro foi avaliada em São Sebastião do Paraíso, nos anos 2010 e 2011 e, em Três Pontas, no ano 2011.

A produtividade foi avaliada, anualmente, em litros de "café da roça" por parcela. Foi realizada a conversão para sacas de $60 \mathrm{~kg}$ de café beneficiado por hectare, por meio da verificação do rendimento de cada parcela, coletando-se 5,0 L de "café da roça", secando-o e beneficiando-o separadamente. Para a avaliação de vigor vegetativo, atribuíram-se notas de 1 a 10, conforme escala arbitrária, proposta por Carvalho et al. (1979). A classificação do café por peneira foi realizada, após o beneficiamento, passando-se uma amostra de 300 gramas pelo conjunto de peneiras (17/64 a 19/ 64). A ferrugem do cafeeiro foi avaliada por escala de notas, variando de 0 a 5 (Petek et al., 2006). Para a cercosporiose, atribuíram-se notas, segundo uma escala, variando de 1 a 5, conforme sugerido por Petek et al. (2007). As avaliações de doenças foram realizadas nos meses de junho/julho, antecedendo a colheita.
Os dados das safras 2010 e 2011 foram agrupados e determinados os valores médios, para serem analisados como biênio. Para essas características, realizou-se a análise de variância conjunta dos dados, por meio do programa computacional SAS (SAS, 2000) e as médias dos tratamentos foram comparadas pelo teste Scott Knott, a $5 \%$ de probabilidade, por meio do programa computacional Genes (Cruz, 2006).

\section{RESULTADOS E DISCUSÃO}

Foram observados efeitos significativos, para todas as características avaliadas e para as fontes de variação, genótipos, blocos e locais, e para a interação, mostrando que os comportamentos dos cultivares não são coincidentes, nos ambientes avaliados, corroborando as conclusões de diversos autores (Carvalho et al. 2006; Pinto et al., 2012a). Os coeficientes de variação (CVs) obtidos foram coerentes com os de outros trabalhos, em que se utilizou a combinação das safras em biênios (Botelho et al., 2010b; Correa et al., 2006), variando entre 7,74, para incidência de cercosporiose, e 21,56\% para produtividade, indicando assim boa precisão experimental (Tabela 2).

O desempenho médio das progênies avaliadas, para produtividade, foi superior, em Três Pontas, quando comparado ao de São Sebastião do Paraíso (Tabela 3). Da mesma forma, Carvalho et al. (2006), avaliando progênies resultantes do cruzamento de cultivares entre Catuaí e Mundo Novo, nestes mesmos ambientes, encontraram maiores produtividades em Três Pontas, o que pode ser atribuído ao melhor equilíbrio das condições químicas do solo desse município (Tabela 1).

No experimento conduzido em Três Pontas, houve a formação de três grupos. Nota-se superioridade da progênie H 6-47-10 Cova 3 sobre as demais progênies e testemunhas, tendo apresentado produtividade média de 65,33 sacas.ha ${ }^{-1}$. Por outro lado, não foram encontradas diferenças significativas entre as progênies estudadas para produtividade em São Sebastião do Paraíso, cujas médias

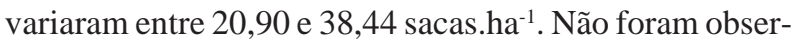
vadas diferenças significativas, quando se compararam os valores médios de produtividade, alcançados pelas progênies cultivadas nos dois locais, com valores variando entre 22,91 e 45,31 sacas.ha ${ }^{-1}$.

Tabela 1. Valores de $\mathrm{pH}$, potássio $(\mathrm{K})$, cálcio $(\mathrm{Ca})$, magnésio $(\mathrm{Mg})$, alumínio $(\mathrm{Al})$, capacidade de troca de cátions a pH 7,0 $(\mathrm{CTC})$, capacidade efetiva de troca de cátions (t), fósforo (P) e saturação por bases (V) em Setembro de 2010, em Fazendas Experimentais de São Sebastião do Paraíso (FESP) e Três Pontas (FETP)

\begin{tabular}{|c|c|c|c|c|c|c|c|c|c|}
\hline \multirow{2}{*}{ Local } & \multirow{2}{*}{$\begin{array}{c}\text { pH } \\
\text { Água }\end{array}$} & $\mathbf{K}$ & $\mathbf{C a}$ & Mg & Al & CTC & $\mathbf{t}$ & $\mathbf{P}$ & $\mathbf{V}$ \\
\hline & & \multicolumn{4}{|c|}{$\mathrm{cmol}_{\mathrm{c}} / \mathrm{dm}^{3}$} & \multicolumn{2}{|c|}{$\mathrm{mg} / \mathrm{dm}^{3}$} & \multicolumn{2}{|c|}{$\%$} \\
\hline$\overline{\text { FESP }}$ & 5,1 & 0,38 & 2,17 & 0,57 & 0,10 & 8,24 & 3,22 & 13,50 & 37,91 \\
\hline FETP & 5,4 & 0,20 & 2,90 & 1,00 & 0,00 & 7,00 & 4,10 & 7,00 & 58,60 \\
\hline
\end{tabular}

Rev. Ceres, Viçosa, v. 62, n.1, p. 062-070, jan/fev, 2015 
O bom desempenho agronômico das progênies estudadas corrobora os resultados obtidos por Correa et al. (2006) e Pinto et al. (2012b), os quais observaram elevadas produtividades de progênies de cruzamentos entre cultivares do grupo Icatu e diferentes cultivares e linhagens de C. arabica. Vale ressaltar ainda que os parentais do Grupo Catuaí, utilizados neste trabalho (Catuaí Amarelo IAC 62 e IAC 17), são genótipos de grande interesse econômico, por combinarem produtividade e adaptabilidade (Nogueira et al., 2005; Botelho et al., 2010b).

Considerando-se a produtividade média dos dois locais, observa-se, ainda na Tabela 3, que dez progênies superaram o desempenho produtivo da testemunha Catuaí Amarelo IAC 62, com destaque para a progênie H 6-4710 Cova 3, com produtividade de 45,31 sacas $\mathrm{ha}^{-1}$. A média geral das progênies foi de 30,9 sacas ha $^{-1}$, superando em $2,23 \%$ a média das três testemunhas $(33,16$ sacas ha $\left.^{-1}\right)$.

Nota-se influência de fatores genéticos e ambientais sobre a classificação dos grãos por tamanho (Tabela 4). Em São Sebastião do Paraíso, houve a formação de quatro grupos de progênies para essa característica. O grupo com maior quantidade de grãos retidos nas peneiras 17 e acima foi constituído por oito progênies, que apresentaram médias entre 61,15 e $71,11 \%$. O segundo agrupamento, constituído por 19 progênies e o cultivar Catucaí Amarelo 2SL, apresentou variação entre 50,64 e $60,37 \%$ de grãos retidos nas peneiras 17 e acima. O terceiro grupo, formado pelas progênies $\mathrm{H}$ 12-37 Cova 5, Catuaí Amarelo IAC 62, H MS Cova 126, H 4-12 Cova 5 e H 4-12 Cova 2, apresentou variação entre 39,31 e $47,41 \%$ de grãos retidos nas peneiras 17 e acima. A progênie H 4-12 Cova 20 e o cultivar Icatu Precoce IAC 3282 formaram o quarto agrupamento, com percentagem de grãos retidos nas peneiras 17 e acima de 34,36 e $32,94 \%$, respectivamente.
Da mesma forma, na FETP, houve também a formação de quatro grupos para a classificação de tamanho de grãos (Tabela 4). O grupo com maior percentagem de grãos nas peneiras 17 e acima teve variação entre 54,73 e 62,13\%, constituído por 13 progênies. O segundo grupo constituiu-se de 17 tratamentos, sendo os cultivares testemunhas Catuaí Amarelo IAC 62 e Catucaí Amarelo 2SL e 15 progênies, com variação entre 44,65 e 53,55\% de grãos retidos nas peneiras 17 acima. As progênies H MS Cova 12 e H MS Cova 13 formam o terceiro agrupamento, com 38,76 e 40,50\% de grãos retidos nas peneiras 17 e acima, respectivamente. As menores percentagens de grãos retidos nas peneiras 17 e acima são apresentados pelas progênies H 4-12 Cova 2, H 4-12 Cova 20, H 4-12 Cova 5 e pelo cultivar Icatu Precoce IAC 3282.

O potencial das progênies, provenientes do cruzamento entre os grupos de cultivares Catuaí e Icatu, para produzir progênies com maiores percentagens de grãos retidos nas peneiras 17 e acima, deve-se ao fato de os cultivares utilizados como genitores apresentarem elevada capacidade de produzir grãos de peneiras superiores, conforme verificado por Dias et al. (2005) e Botelho et al. (2010b).

Quando se avalia a percentagem de grãos, retidos nas peneiras 17 e acima, na média dos ambientes, nota-se a formação de três grupos (Tabela 4). O grupo com maior percentual de grãos nas peneiras 17 e acima foi constituído por 16 progênies, com valores entre 55,38 e 65,54\%. O grupo com as menores percentagens de grãos nas peneiras 17 e acima foi composto pelas progênies H 4-12 Cova 2, H 4-12 Cova 5 e H 4-12 Cova 20 e pelo cultivar Icatu Precoce IAC 3282. Os demais genótipos constituíram o grupo com valores intermediários.

O experimento no município de São Sebastião do Paraíso apresentou valores inferiores de vigor vegetativo (Tabela 4 ), sendo seus efeitos notados na

Tabela 2. Resultados da análise de variância para produtividade (Prod) em sacas.ha-1 ${ }^{-1}$, retenção em peneira 17 e acima (\%), notas para vigor vegetativo, reação à ferrugem (Ferr.) e cercosporiose (Cerc.) de 33 progênies e três cultivares de cafeeiros avaliados em Fazendas Experimentais de São Sebastião do Paraíso (FESP) e Três Pontas (FETP)

\begin{tabular}{|c|c|c|c|c|c|c|}
\hline \multirow{2}{*}{ FV } & \multirow{2}{*}{ GL } & \multicolumn{5}{|c|}{$\mathbf{Q M}$} \\
\hline & & Prod. & Peneira & Vigor & Ferr. & Cerc. \\
\hline Local & 1 & $6465,7591 *$ & $1473,9202 *$ & $58,6979^{*}$ & 0,4257 & $0,671^{*}$ \\
\hline Rep (local) & 4 & $901,9396^{*}$ & 95,5956* & $2,3054^{*}$ & $1,6769^{*}$ & $0,460 *$ \\
\hline Bloco (loc*rep) & 30 & $5039,6342^{*}$ & $193,2804 *$ & $1,8647^{*}$ & $1,2921^{*}$ & $0,141^{*}$ \\
\hline Trat. & 35 & $3678,9264^{*}$ & $400,81064 *$ & $0,7925^{*}$ & $0,3895^{*}$ & $0,104^{*}$ \\
\hline Loc*trat. & 35 & $4095,3574 *$ & $94,54586^{*}$ & 0,2205 & 0,2160 & 0,0397 \\
\hline Erro & 110 & 5876,3201 & 38,06719 & 0,2868 & 0,1552 & 0,0619 \\
\hline $\mathrm{CV}(\%)$ & & 21,56 & 11,81 & 8,73 & 12,97 & 7,74 \\
\hline Média & & 33,89 & 52,22 & 6,13 & 3,03 & 3,21 \\
\hline
\end{tabular}

*Significativo a 5\% de probabilidade, pelo Teste $\mathrm{F}$. 
obtenção de menor produtividade nesse município, já que são características correlacionadas (Petek et al., 2002). Neste experimento, houve a formação de dois grupos, nos quais 16 progênies constituíram o grupo com valores superiores de vigor vegetativo, variando entre 5,68 e 7,16. O grupo com notas inferiores foi constituído por 17 progênies e as três testemunhas. Em Três Pontas e na média dos dois ambientes, não houve diferenças significativas para vigor vegetativo. As notas, em Três Pontas, apresentaram variação entre 5,74 e 7,16 e, na média dos dois ambientes, a variação foi de 5,02 a 6,98 .
Em programas de melhoramento genético de cafeeiro busca-se um ideótipo cujo desempenho abranja, além de outras características, elevada capacidade produtiva e aumento no tamanho dos grãos (Ferreira et al., 2005). Observando-se as Tabelas 3 e 4, é importante ressaltar o comportamento da progênie H 6-47-10 Cova 3, que apresentou a maior produtividade em Três Pontas, alta percentagem de grãos nas peneiras 17 acima, em São Sebastião do Paraíso e elevado vigor vegetativo, nos dois ambientes estudados.

Para as notas de reação à ferrugem, não foi observada interação entre os genótipos e os ambientes (Tabelas 2 e

Tabela 3. Médias de produtividade (sacas ha ${ }^{-1}$ ) de 33 progênies e três cultivares de cafeeiros avaliados nas safras 2009/2010 e 2010/ 2011 nas Fazendas Experimentais de São Sebastião do Paraíso (FESP) e Três Pontas (FETP)

\begin{tabular}{|c|c|c|c|}
\hline Progênies & FESP & FETP & Média \\
\hline H 7-31 Cv 3 & $24,77 \mathrm{aB}$ & $47,22 \mathrm{bA}$ & $35,99 \mathrm{a}$ \\
\hline H $15-20$ Cv 3 & $20,90 \mathrm{aB}$ & $34,14 \mathrm{cA}$ & $27,52 \mathrm{a}$ \\
\hline H 15-20 Cv 11 & $30,12 \mathrm{aB}$ & $51,24 \mathrm{bA}$ & $40,68 \mathrm{a}$ \\
\hline H 12-37 Cv 5 & $30,57 \mathrm{aB}$ & $40,97 \mathrm{bA}$ & $35,77 \mathrm{a}$ \\
\hline H $12-37$ Cv 18 & $23,92 \mathrm{aA}$ & $34,88 \mathrm{cA}$ & $29,40 \mathrm{a}$ \\
\hline H 4-12 Cv 2 & $35,26 \mathrm{aA}$ & $34,90 \mathrm{cA}$ & $35,08 \mathrm{a}$ \\
\hline H $4-12$ Cv 5 & $24,85 \mathrm{aA}$ & $39,30 \mathrm{bA}$ & $32,08 \mathrm{a}$ \\
\hline H 4-12 Cv 20 & $31,10 \mathrm{aA}$ & $43,03 \mathrm{bA}$ & $37,07 \mathrm{a}$ \\
\hline H MS Cv 13 & $25,21 \mathrm{aB}$ & $41,34 \mathrm{bA}$ & $33,27 \mathrm{a}$ \\
\hline H MS Cv 14 & $31,41 \mathrm{aA}$ & $34,53 \mathrm{cA}$ & $32,97 \mathrm{a}$ \\
\hline H 4-35-11 Cv 10 & $28,57 \mathrm{aB}$ & $47,07 \mathrm{bA}$ & $37,67 \mathrm{a}$ \\
\hline H 4-35-11 Cv 16 & $36,40 \mathrm{aA}$ & $44,32 \mathrm{bA}$ & $40,36 \mathrm{a}$ \\
\hline H 19-66-31 Cv 9 & $35,17 \mathrm{aB}$ & $48,79 \mathrm{bA}$ & $41,98 \mathrm{a}$ \\
\hline H 6-47-10 Cv 3 & $25,29 \mathrm{aB}$ & $65,33 \mathrm{aA}$ & $45,31 \mathrm{a}$ \\
\hline H 6-47-10 Cv 16 & $29,89 \mathrm{aA}$ & $32,19 \mathrm{cA}$ & $31,04 \mathrm{a}$ \\
\hline Н $31-06-16$ Cv 8 & $23,27 \mathrm{aA}$ & $35,37 \mathrm{cA}$ & $29,32 \mathrm{a}$ \\
\hline H 31-06-16 Cv 12 & $22,26 \mathrm{aB}$ & $44,26 \mathrm{bA}$ & $33,26 \mathrm{a}$ \\
\hline H MS Cv 11 & $31,85 \mathrm{aA}$ & $41,00 \mathrm{bA}$ & $36,42 \mathrm{a}$ \\
\hline H MS Cv 12 & $35,37 \mathrm{aA}$ & $25,96 \mathrm{cA}$ & $30,66 \mathrm{a}$ \\
\hline H 1-41-19 Cv 1 & $36,63 \mathrm{aA}$ & $32,08 \mathrm{cA}$ & $34,35 \mathrm{a}$ \\
\hline H 1-41-19 Cv 3 & $29,60 \mathrm{aA}$ & $36,33 \mathrm{cA}$ & $31,61 \mathrm{a}$ \\
\hline H 1-41-19 Cv 14 & $38,44 \mathrm{aA}$ & $41,50 \mathrm{bA}$ & $39,97 \mathrm{a}$ \\
\hline H $16-55-09$ Cv 3 & $29,63 \mathrm{aA}$ & $36,83 \mathrm{cA}$ & $33,23 \mathrm{a}$ \\
\hline H $16-55-09$ Cv 6 & $21,47 \mathrm{aB}$ & $41,71 \mathrm{bA}$ & $31,59 \mathrm{a}$ \\
\hline H MS Cv 126 & $25,03 \mathrm{aA}$ & $25,80 \mathrm{cA}$ & $25,42 \mathrm{a}$ \\
\hline H MS Cv 149 & $28,69 \mathrm{aB}$ & $42,92 \mathrm{bA}$ & $35,80 \mathrm{a}$ \\
\hline H MS Cv 178 & $33,79 \mathrm{aA}$ & $37,42 \mathrm{cA}$ & $35,56 \mathrm{a}$ \\
\hline H 1-41-23 Cv 42 & $26,42 \mathrm{aA}$ & $33,21 \mathrm{cA}$ & $29,81 \mathrm{a}$ \\
\hline H 1-41-23 Cv 73 & $22,77 \mathrm{aA}$ & $23,04 \mathrm{cA}$ & $22,91 \mathrm{a}$ \\
\hline H 1-41-23 Cv 156 & $26,39 \mathrm{aA}$ & $38,75 \mathrm{bA}$ & $32,57 \mathrm{a}$ \\
\hline H $38-22-15$ Cv 125 & $28,10 \mathrm{aB}$ & $46,83 \mathrm{bA}$ & $37,47 \mathrm{a}$ \\
\hline H 38-22-15 Cv 134 & $35,25 \mathrm{aA}$ & $39,74 \mathrm{bA}$ & $37,49 \mathrm{a}$ \\
\hline H $38-22-15$ Cv 165 & $27,12 \mathrm{aA}$ & $27,24 \mathrm{cA}$ & $27,18 \mathrm{a}$ \\
\hline Catuaí Amarelo IAC 62 & $28,80 \mathrm{aB}$ & $43,19 \mathrm{bA}$ & $36,00 \mathrm{a}$ \\
\hline Catucaí Amarelo 2SL & $23,19 \mathrm{aB}$ & $43,67 \mathrm{bA}$ & $33,43 \mathrm{a}$ \\
\hline Icatu Precoce IAC 3282 & $18,84 \mathrm{aB}$ & $41,24 \mathrm{bA}$ & $30,04 \mathrm{a}$ \\
\hline Média & $28,43 \mathrm{~B}$ & $39,37 \mathrm{~A}$ & 33,90 \\
\hline
\end{tabular}

Médias seguidas de mesma letra minúscula, na coluna, e maiúscula, na linha, não diferem entre si pelo Teste de Scott Knott, a 5\% de significância. 
5). A partir do desdobramento de tratamentos dentro de ambientes, verifica-se que em São Sebastião do Paraíso não houve diferenças significativas entre os tratamentos, assim como para a média dos municípios de São Sebastião do Paraíso e Três Pontas. Em Três Pontas, observou-se a formação de dois grupos, nos quais os cultivares Catucaí Amarelo 2SL e Icatu Precoce IAC 3282, que são considerados resistentes, foram situados no grupo com maior ocorrência de ferrugem, enquanto 29 progênies apresentaram menor infestação, comparada com a das testemunhas. Merece destaque a progênie H 6-47-10 Cova 3, que obteve a maior produtividade, na
Fazenda Experimental de Três Pontas, e se manteve entre as progênies com menor ocorrência de ferrugem, naquele local.

De maneira geral, observa-se que a maioria dos materiais estudados (com exceção da progênie H 7-31 Cova 3, no município de Três Pontas) apresentaram notas de reação à ferrugem entre 2,22 e 3,95, nos dois locais e na média, podendo ser classificadas como plantas resistentes e moderadamente susceptíveis (Petek et al., 2006). De acordo com Fazuoli et al. (1983), a associação de genes das espécies C. canephora e C. arabica mostrou-se altamente favorável nas populações de Icatu,

Tabela 4. Percentagem média de grãos retidos em peneira 17 e acima e notas de vigor vegetativo de 33 progênies e três cultivares de cafeeiros avaliados nas safras 2010 e 2011 nas Fazendas Experimentais de São Sebastião do Paraíso (FESP) e Três Pontas (FETP)

\begin{tabular}{|c|c|c|c|c|c|c|}
\hline \multirow{2}{*}{ Tratamento } & \multicolumn{3}{|c|}{ Peneira } & \multicolumn{3}{|c|}{ Vigor vegetativo } \\
\hline & FESP & FETP & Média & FESP & FETP & Média \\
\hline H 7-31 Cv 3 & $56,87 \mathrm{bA}$ & $48,23 \mathrm{bA}$ & $52,55 \mathrm{~b}$ & $5,24 \mathrm{bB}$ & $6,72 \mathrm{aA}$ & $5,98 \mathrm{a}$ \\
\hline H $15-20 \mathrm{Cv} 3$ & $62,86 \mathrm{aA}$ & $47,90 \mathrm{bB}$ & $55,38 \mathrm{a}$ & $5,21 \mathrm{bB}$ & 7,09 aA & $6,15 \mathrm{a}$ \\
\hline H $15-20$ Cv 11 & $54,94 \mathrm{bA}$ & $50,42 \mathrm{bA}$ & $52,68 \mathrm{~b}$ & $5,47 \mathrm{bA}$ & $6,19 \mathrm{aA}$ & $5,83 \mathrm{a}$ \\
\hline H 12-37 Cv 5 & $47,41 \mathrm{cA}$ & $56,33 \mathrm{aA}$ & $51,87 \mathrm{~b}$ & $5,90 \mathrm{aB}$ & $6,88 \mathrm{aA}$ & $6,39 \mathrm{a}$ \\
\hline H $12-37$ Cv 18 & $57,61 \mathrm{bA}$ & $48,89 \mathrm{bA}$ & $53,25 \mathrm{~b}$ & $5,43 \mathrm{bB}$ & $6,49 \mathrm{aA}$ & $5,96 \mathrm{a}$ \\
\hline $\mathrm{H} 4-12 \mathrm{Cv} 2$ & $39,31 \mathrm{cA}$ & $29,71 \mathrm{dA}$ & $34,51 \mathrm{c}$ & $6,20 \mathrm{aA}$ & $6,58 \mathrm{aA}$ & $6,39 \mathrm{a}$ \\
\hline H 4-12 Cv 5 & $43,39 \mathrm{cA}$ & $19,33 \mathrm{~dB}$ & $30,86 \mathrm{c}$ & $6,72 \mathrm{aA}$ & $6,96 \mathrm{aA}$ & $6,84 \mathrm{a}$ \\
\hline H 4-12 Cv 20 & $34,36 \mathrm{dA}$ & $24,76 \mathrm{dA}$ & $29,56 \mathrm{c}$ & $5,88 \mathrm{aA}$ & $6,76 \mathrm{aA}$ & $6,32 \mathrm{a}$ \\
\hline H MS Cv13 & $52,02 \mathrm{bA}$ & $40,50 \mathrm{cB}$ & $46,26 \mathrm{~b}$ & $5,63 \mathrm{bB}$ & $7,01 \mathrm{aA}$ & $6,32 \mathrm{a}$ \\
\hline H MS Cv 14 & $57,10 \mathrm{bA}$ & $47,02 \mathrm{bA}$ & $52,06 \mathrm{~b}$ & $5,98 \mathrm{aA}$ & $6,94 \mathrm{aA}$ & $6,46 a$ \\
\hline H 4-35-11 Cv 10 & $58,43 \mathrm{bA}$ & $56,21 \mathrm{aA}$ & $57,32 \mathrm{a}$ & $5,95 \mathrm{aA}$ & $6,63 \mathrm{aA}$ & $6,29 \mathrm{a}$ \\
\hline H 4-35-11 Cv 16 & $56,90 \mathrm{bA}$ & $56,90 \mathrm{aA}$ & $56,90 \mathrm{a}$ & $5,89 \mathrm{aA}$ & $6,63 \mathrm{aA}$ & $6,26 \mathrm{a}$ \\
\hline H 19-66-31 Cv 9 & $50,69 \mathrm{bA}$ & $45,79 \mathrm{bA}$ & $48,24 \mathrm{~b}$ & $5,34 \mathrm{bB}$ & $6,62 \mathrm{aA}$ & $6,98 \mathrm{a}$ \\
\hline H 6-47-10 Cv 3 & $67,07 \mathrm{aA}$ & $51,09 \mathrm{bB}$ & 59,08 a & $5,92 \mathrm{aB}$ & $7,16 \mathrm{aA}$ & $6,54 \mathrm{a}$ \\
\hline H 6-47-10 Cv 16 & $62,31 \mathrm{aA}$ & $53,55 \mathrm{bA}$ & $57,93 \mathrm{a}$ & $6,25 \mathrm{aA}$ & $6,99 \mathrm{aA}$ & $6,62 \mathrm{a}$ \\
\hline H $31-06-16$ Cv 8 & $54,01 \mathrm{bA}$ & $58,31 \mathrm{aA}$ & 56,16 a & $5,48 \mathrm{bA}$ & $6,36 \mathrm{aA}$ & $5,92 \mathrm{a}$ \\
\hline H 31-06-16 Cv 12 & $55,24 \mathrm{bA}$ & $53,42 \mathrm{bA}$ & $54,33 \mathrm{~b}$ & $5,41 \mathrm{bA}$ & $5,77 \mathrm{aA}$ & $5,59 \mathrm{a}$ \\
\hline H MS Cv 11 & $59,17 \mathrm{bA}$ & $48,85 \mathrm{bA}$ & $54,01 \mathrm{~b}$ & $6,39 \mathrm{aA}$ & $7,01 \mathrm{aA}$ & $6,70 \mathrm{a}$ \\
\hline H MS Cv 12 & $53,16 \mathrm{bA}$ & $38,76 \mathrm{cB}$ & $45,96 \mathrm{~b}$ & $5,68 \mathrm{aA}$ & $6,22 \mathrm{aA}$ & $5,95 \mathrm{a}$ \\
\hline H 1-41-19 Cv 1 & $53,06 \mathrm{bA}$ & $59,80 \mathrm{aA}$ & $56,43 \mathrm{a}$ & $5,59 \mathrm{bB}$ & $6,95 \mathrm{aA}$ & $6,27 \mathrm{a}$ \\
\hline H $1-41-19$ Cv 3 & $66,48 \mathrm{aA}$ & $57,30 \mathrm{aA}$ & $61,89 \mathrm{a}$ & $4,98 \mathrm{bB}$ & $6,94 \mathrm{aA}$ & $5,96 \mathrm{a}$ \\
\hline H 1-41-19 Cv 14 & $59,11 \mathrm{bA}$ & $62,13 \mathrm{aA}$ & $60,62 \mathrm{a}$ & $5,69 \mathrm{aB}$ & $6,73 \mathrm{aA}$ & $6,21 \mathrm{a}$ \\
\hline H $16-55-09$ Cv 3 & $60,37 \mathrm{bA}$ & $61,23 \mathrm{aA}$ & $60,80 \mathrm{a}$ & $5,52 \mathrm{bB}$ & $6,76 \mathrm{aA}$ & $6,14 \mathrm{a}$ \\
\hline H $16-55-09$ Cv 6 & $53,17 \mathrm{bA}$ & $54,73 \mathrm{aA}$ & $53,95 \mathrm{~b}$ & $5,28 \mathrm{bB}$ & $6,60 \mathrm{aA}$ & $5,94 \mathrm{a}$ \\
\hline H MS Cv 126 & $43,79 \mathrm{cB}$ & $59,97 \mathrm{aA}$ & $51,88 \mathrm{~b}$ & $5,49 \mathrm{bB}$ & 7,09 aA & $6,29 \mathrm{a}$ \\
\hline H MS Cv 149 & $71,11 \mathrm{aA}$ & $59,29 \mathrm{aB}$ & $65,20 \mathrm{a}$ & $6,01 \mathrm{aA}$ & $6,85 \mathrm{aA}$ & $6,43 \mathrm{a}$ \\
\hline H MS Cv 178 & $70,94 \mathrm{aA}$ & $60,14 \mathrm{aB}$ & $65,54 \mathrm{a}$ & $6,53 \mathrm{aA}$ & $7,13 \mathrm{aA}$ & $6,83 \mathrm{a}$ \\
\hline H 1-41-23 Cv 42 & $56,55 \mathrm{bB}$ & $44,65 \mathrm{bA}$ & $50,60 \mathrm{~b}$ & $5,38 \mathrm{bB}$ & $6,40 \mathrm{aA}$ & $5,89 \mathrm{a}$ \\
\hline H 1-41-23 Cv 73 & $52,22 \mathrm{bA}$ & $61,50 \mathrm{aA}$ & $56,86 \mathrm{a}$ & $5,22 \mathrm{bB}$ & $6,74 \mathrm{aA}$ & $5,98 \mathrm{a}$ \\
\hline H 1-41-23 Cv 156 & $61,15 \mathrm{aA}$ & $50,83 \mathrm{bA}$ & $55,99 \mathrm{a}$ & $5,77 \mathrm{aA}$ & $6,59 \mathrm{aA}$ & $6,18 \mathrm{a}$ \\
\hline H $38-22-15$ Cv 125 & $52,29 \mathrm{Ba}$ & $50,67 \mathrm{bA}$ & $51,48 \mathrm{~b}$ & $5,75 \mathrm{aA}$ & $6,57 \mathrm{aA}$ & $6,16 \mathrm{a}$ \\
\hline H $38-22-15$ Cv 134 & $58,17 \mathrm{Ba}$ & $52,73 \mathrm{bA}$ & $55,45 \mathrm{a}$ & $5,46 \mathrm{bA}$ & $6,34 \mathrm{aA}$ & $5,90 \mathrm{a}$ \\
\hline H 38-22-15 Cv 165 & $66,19 \mathrm{Aa}$ & $51,73 \mathrm{bB}$ & 58,96 a & $5,09 \mathrm{bB}$ & $6,29 \mathrm{aA}$ & $5,69 \mathrm{a}$ \\
\hline Cat. Amar. IAC 62 & $44,00 \mathrm{cA}$ & $45,26 \mathrm{bA}$ & $44,63 \mathrm{~b}$ & $5,36 \mathrm{bB}$ & $6,56 \mathrm{aA}$ & $5,96 \mathrm{a}$ \\
\hline Catucaí Am. 2SL & $50,64 \mathrm{Ba}$ & $50,32 \mathrm{bA}$ & $50,48 \mathrm{~b}$ & $4,37 \mathrm{bB}$ & $6,07 \mathrm{aA}$ & $5,22 \mathrm{a}$ \\
\hline Icatu IAC 3282 & $32,94 \mathrm{Da}$ & $27,70 \mathrm{dA}$ & $30,32 \mathrm{c}$ & $4,30 \mathrm{bB}$ & $5,74 \mathrm{aA}$ & $5,02 \mathrm{a}$ \\
\hline Média & $54,83 \mathrm{~A}$ & $49,60 \mathrm{~B}$ & 52,22 & $5,60 \mathrm{~B}$ & $6,65 \mathrm{~A}$ & 6,13 \\
\hline
\end{tabular}

Médias seguidas de mesma letra minúscula, na coluna, e maiúscula, na linha, não diferem entre si pelo Teste de Scott Knott, a 5\% de significância. 
que, além da produtividade elevada, apresentam outras características favoráveis, como bom aspecto vegetativo e boa qualidade da bebida e, principalmente, resistência a $H$. vastatrix. Entretanto, os autores ainda ressaltam que, no Brasil, outras raças de $H$. vastatrix vêm sendo identificadas com frequência relativamente alta, o que dificulta os trabalhos de seleção.

A infestação de cercosporiose teve maior ocorrência em São Sebastião do Paraíso e, assim como a menor produtividade, a maior incidência de cercosporiose pode estar relacionada com aspectos de fertilidade do solo, haja vista a grande influência da nutrição mineral do cafeeiro na ocorrência da doença (Santos et al., 2008).

O excesso de potássio favorece a ocorrência da cercosporiose (Pozza et al., 2001; Garcia Junior et al., 2003), ao comprometer a absorção de cálcio e magnésio. De acordo com os teores nutricionais apresentados na Tabela 1, em São Sebastião do Paraíso, é observado um desequilíbrio da relação $\mathrm{Ca} / \mathrm{K}$, que está em 5,71 , sendo que em Três Pontas esta relação é de 14,50. A relação $\mathrm{Mg} / \mathrm{K}$ está em 1,50, em São Sebastião do Paraíso e 5,00, em Três Pontas. Portanto, é evidente que em São Sebastião do Paraíso os teores de cálcio e magnésio estão

Tabela 5. Notas de reação à ferrugem e cercosporiose de 33 progênies e três cultivares de cafeeiros avaliados em 2010 e 2011 em Fazendas Experimentais de São Sebastião do Paraíso (FESP) e Três Pontas (FETP)

\begin{tabular}{|c|c|c|c|c|c|c|}
\hline \multirow{2}{*}{ Tratamento } & \multicolumn{3}{|c|}{ Reação à ferrugem } & \multicolumn{3}{|c|}{ Reação à cercosporiose } \\
\hline & FESP & FETP & Média & FESP & FETP & Média \\
\hline H 7-31 Cv 3 & $3,39 \mathrm{aA}$ & $4,09 \mathrm{aA}$ & $3,74 \mathrm{a}$ & $3,19 \mathrm{aA}$ & $3,11 \mathrm{aA}$ & $3,15 \mathrm{a}$ \\
\hline H $15-20 \mathrm{Cv} 3$ & $2,65 \mathrm{aB}$ & $3,61 \mathrm{aA}$ & $3,13 \mathrm{a}$ & $2,93 \mathrm{aA}$ & $2,75 \mathrm{aA}$ & $3,11 \mathrm{a}$ \\
\hline H $15-20 \mathrm{Cv} 11$ & $3,11 \mathrm{aA}$ & $3,35 \mathrm{aA}$ & $3,23 \mathrm{a}$ & $3,29 \mathrm{aA}$ & $3,31 \mathrm{aA}$ & $3,30 \mathrm{a}$ \\
\hline H $12-37$ Cv 5 & $3,02 \mathrm{aA}$ & $3,02 \mathrm{bA}$ & $3,02 \mathrm{a}$ & $3,34 \mathrm{aA}$ & $3,06 \mathrm{aA}$ & $3,20 \mathrm{a}$ \\
\hline H $12-37 \mathrm{Cv} 18$ & $3,77 \mathrm{aA}$ & $3,59 \mathrm{aA}$ & $3,68 \mathrm{a}$ & $3,22 \mathrm{aA}$ & $3,10 \mathrm{aA}$ & $3,16 \mathrm{a}$ \\
\hline $\mathrm{H} 4-12 \mathrm{Cv} 2$ & $2,88 \mathrm{aA}$ & $2,22 \mathrm{bA}$ & $2,55 \mathrm{a}$ & $3,04 \mathrm{aA}$ & $2,98 \mathrm{aA}$ & $3,01 \mathrm{a}$ \\
\hline H $4-12$ Cv 5 & $3,02 \mathrm{aA}$ & $2,90 \mathrm{bA}$ & $2,96 \mathrm{a}$ & $2,91 \mathrm{aA}$ & $2,97 \mathrm{aA}$ & $2,94 \mathrm{a}$ \\
\hline H 4-12 Cv 20 & $2,87 \mathrm{aA}$ & $3,09 \mathrm{bA}$ & $2,98 \mathrm{a}$ & $2,99 \mathrm{aA}$ & $3,09 \mathrm{aA}$ & $3,04 \mathrm{a}$ \\
\hline H MS Cv 13 & $2,80 \mathrm{aA}$ & $2,92 \mathrm{bA}$ & $2,86 a$ & $3,26 \mathrm{aA}$ & $3,06 \mathrm{aA}$ & $3,16 \mathrm{a}$ \\
\hline H MS Cv 14 & $3,43 \mathrm{aA}$ & $3,07 \mathrm{bA}$ & $3,25 \mathrm{a}$ & $3,42 \mathrm{aA}$ & $3,10 \mathrm{aA}$ & $3,26 \mathrm{a}$ \\
\hline H 4-35-11 Cv 10 & $3,15 \mathrm{aA}$ & $2,89 \mathrm{bA}$ & $3,02 \mathrm{a}$ & $3,31 \mathrm{aA}$ & $3,17 \mathrm{aA}$ & $3,24 \mathrm{a}$ \\
\hline H 4-35-11 Cv 16 & $2,95 \mathrm{aA}$ & $2,99 \mathrm{bA}$ & $2,97 \mathrm{a}$ & $3,33 \mathrm{aA}$ & $3,09 \mathrm{aA}$ & $3,21 \mathrm{a}$ \\
\hline H 19-66-31 Cv 9 & $2,90 \mathrm{aA}$ & $2,84 \mathrm{bA}$ & $2,87 \mathrm{a}$ & $3,45 \mathrm{aA}$ & $3,29 \mathrm{aA}$ & $3,37 \mathrm{a}$ \\
\hline H 6-47-10 Cv 3 & $3,08 \mathrm{aA}$ & $2,74 \mathrm{bA}$ & $2,91 \mathrm{a}$ & $3,38 \mathrm{aA}$ & $3,08 \mathrm{aA}$ & $3,23 \mathrm{a}$ \\
\hline H 6-47-10 Cv 16 & $3,03 \mathrm{aA}$ & $2,75 \mathrm{bA}$ & $2,89 \mathrm{a}$ & $3,23 \mathrm{aA}$ & $3,31 \mathrm{aA}$ & $3,27 \mathrm{a}$ \\
\hline Н 31-06-16 Cv 8 & $2,82 \mathrm{aA}$ & $2,92 \mathrm{bA}$ & $2,87 \mathrm{a}$ & $3,14 \mathrm{aA}$ & $3,34 \mathrm{aA}$ & $3,24 \mathrm{a}$ \\
\hline H 31-06-16 Cv 12 & $2,89 \mathrm{aA}$ & $3,03 \mathrm{bA}$ & $2,96 \mathrm{a}$ & $3,44 \mathrm{aA}$ & $3,32 \mathrm{aA}$ & $3,38 \mathrm{a}$ \\
\hline H MS Cv 11 & $3,07 \mathrm{aA}$ & $2,73 \mathrm{bA}$ & $2,90 \mathrm{a}$ & $2,98 \mathrm{aA}$ & $3,06 \mathrm{aA}$ & $3,02 \mathrm{a}$ \\
\hline H MS Cv 12 & $2,81 \mathrm{aA}$ & $3,47 \mathrm{aA}$ & $3,14 \mathrm{a}$ & $3,34 \mathrm{aA}$ & $3,44 \mathrm{aA}$ & $3,39 \mathrm{a}$ \\
\hline H 1-41-19 Cv 1 & $3,06 \mathrm{aA}$ & $3,40 \mathrm{aA}$ & $3,23 \mathrm{a}$ & $3,30 \mathrm{aA}$ & $3,14 \mathrm{aA}$ & $3,22 \mathrm{a}$ \\
\hline H $1-41-19$ Cv 3 & $3,00 \mathrm{aA}$ & $2,62 \mathrm{bA}$ & $2,81 \mathrm{a}$ & $3,38 \mathrm{aA}$ & $3,08 \mathrm{aA}$ & $3,23 \mathrm{a}$ \\
\hline H 1-41-19 Cv 14 & $2,70 \mathrm{aA}$ & $2,28 \mathrm{bA}$ & $2,49 a$ & $3,11 \mathrm{aA}$ & $3,19 \mathrm{aA}$ & $3,15 \mathrm{a}$ \\
\hline H $16-55-09$ Cv 3 & $2,94 \mathrm{aA}$ & $3,14 \mathrm{bA}$ & $3,04 \mathrm{a}$ & $3,38 \mathrm{aA}$ & $3,26 \mathrm{aA}$ & $3,32 \mathrm{a}$ \\
\hline H $16-55-09$ Cv 6 & $2,87 \mathrm{aA}$ & $3,21 \mathrm{bA}$ & $3,04 \mathrm{a}$ & $3,29 \mathrm{aA}$ & $3,29 \mathrm{aA}$ & $3,29 \mathrm{a}$ \\
\hline H MS Cv 126 & $2,56 \mathrm{aA}$ & $2,72 \mathrm{bA}$ & $2,64 \mathrm{a}$ & $3,30 \mathrm{aA}$ & $2,76 \mathrm{aB}$ & $3,03 \mathrm{a}$ \\
\hline H MS Cv 149 & $3,11 \mathrm{aA}$ & $2,93 \mathrm{bA}$ & $3,02 \mathrm{a}$ & $3,29 \mathrm{aA}$ & $3,09 \mathrm{aA}$ & $3,19 \mathrm{a}$ \\
\hline H MS Cv 178 & $2,98 \mathrm{aA}$ & $2,72 \mathrm{bA}$ & $2,85 \mathrm{a}$ & $3,38 \mathrm{aA}$ & $3,02 \mathrm{aA}$ & $3,20 \mathrm{a}$ \\
\hline H 1-41-23 Cv 42 & $2,93 \mathrm{aA}$ & $3,05 \mathrm{bA}$ & $2,99 \mathrm{a}$ & $3,48 \mathrm{aA}$ & $3,58 \mathrm{aA}$ & $3,53 \mathrm{a}$ \\
\hline H 1-41-23 Cv 73 & $2,62 \mathrm{aB}$ & $3,50 \mathrm{aA}$ & $3,06 \mathrm{a}$ & $3,37 \mathrm{aA}$ & $2,91 \mathrm{aB}$ & $3,14 \mathrm{a}$ \\
\hline H 1-41-23 Cv 156 & $2,83 \mathrm{aA}$ & $3,01 \mathrm{bA}$ & $2,92 \mathrm{a}$ & $3,31 \mathrm{aA}$ & $3,03 \mathrm{aA}$ & $3,17 \mathrm{a}$ \\
\hline H 38-22-15 Cv125 & $2,93 \mathrm{aA}$ & $2,77 \mathrm{bA}$ & $2,85 \mathrm{a}$ & $3,32 \mathrm{aA}$ & $3,32 \mathrm{aA}$ & $3,32 \mathrm{a}$ \\
\hline H 38-22-15 Cv 134 & $2,92 \mathrm{aA}$ & $2,80 \mathrm{bA}$ & $2,86 \mathrm{a}$ & $3,44 \mathrm{aA}$ & $3,38 \mathrm{aA}$ & $3,41 \mathrm{a}$ \\
\hline H 38-22-15 Cv 165 & $2,85 \mathrm{aA}$ & $3,15 \mathrm{bA}$ & $3,00 \mathrm{a}$ & $3,43 \mathrm{aA}$ & $3,39 \mathrm{aA}$ & $3,41 \mathrm{a}$ \\
\hline Catuaí Am. IAC62 & $3,36 \mathrm{aA}$ & $3,74 \mathrm{aA}$ & $3,55 \mathrm{a}$ & $3,29 \mathrm{aA}$ & $3,19 \mathrm{aA}$ & $3,24 \mathrm{a}$ \\
\hline Catucaí Am. 2SL & $3,42 \mathrm{aA}$ & $3,56 \mathrm{aA}$ & $3,49 \mathrm{a}$ & $3,07 \mathrm{aA}$ & $3,25 \mathrm{aA}$ & $3,16 \mathrm{a}$ \\
\hline Icatu IAC 3282 & $2,85 \mathrm{aB}$ & $3,95 \mathrm{aA}$ & $3,40 \mathrm{a}$ & $3,19 \mathrm{aA}$ & $3,03 \mathrm{aA}$ & $3,11 \mathrm{a}$ \\
\hline Média & $2,99 \mathrm{~A}$ & $3,07 \mathrm{~A}$ & 3,03 & $3,26 \mathrm{~A}$ & $3,15 \mathrm{~B}$ & 3,21 \\
\hline
\end{tabular}

Médias seguidas de mesma letra minúscula, na coluna, e maiúscula, na linha, não diferem entre si pelo Teste de Scott Knott, a 5\% de significância.

Rev. Ceres, Viçosa, v. 62, n.1, p. 062-070, jan/fev, 2015 
baixos, podendo-se atribuir essa maior infestação de cercosporiose neste município, entre outros fatores, ao desequilíbrio nutricional entre cálcio, magnésio e potássio.

Em cada um dos ambientes, a incidência de cercosporiose não apresentou diferenças significativas entre os tratamentos avaliados. Em São Sebastião do Paraíso, as notas tiveram variação entre 2,91 e 3,48 pontos e, em Três Pontas, a variação foi de 2,75 a 3,58, podendo ser interpretadas como valores indicativos de resistência moderada a susceptível e corroborando resultados obtidos por diversos autores, que constataram comportamento moderadamente resistente à cercosporiose, em cultivares do grupo Catuaí, e comportamento susceptível, no cultivar Icatu Vermelho (Patrício et al., 2010; Dell'Acqua et al., 2011), parentais utilizados no cruzamento das progênies avaliadas neste trabalho. Ressalta-se, ainda, que uma nutrição suficiente e equilibrada pode levar à resistência induzida à cercosporiose (Petek et al., 2007).

\section{CONCLUSÕES}

O desempenho das progênies avaliadas, para produtividade, foi superior em Três Pontas, quando comparado com o observado em São Sebastião do Paraíso.

A progênie H 6-47-10 Cova 3 apresenta produtividade superior à dos demais progênies e cultivares, com características favoráveis de tamanho de grãos, vigor vegetativo, reação à ferrugem e à cercosporiose.

\section{AGRADECIMENTOS}

À Fapemig, ao Consorcio de Pesquisa Café e ao Instituto Nacional de Ciência e Tecnologia do Café (INCT Café/CNPq) pelo apoio financeiro ao projeto e ao $\mathrm{CNPq}$ pela concessão da bolsa de mestrado (CAG) e PNPD (JCR).

\section{REFERÊNCIAS}

Botelho CE, Rezende JC de, Carvalho GR, Carvalho AM de, Andrade VT \& Barbosa CR. (2010a) Adaptabilidade e estabilidade fenotípica de cultivares de café arábica em Minas Gerais. Pesquisa Agropecuária Brasileira, 45:1404-1411.

Botelho CE, Mendes ANG, Carvalho GR, Bartholo GF \& Carvalho SP (2010b) Seleção de progênies $F_{4}$ de cafeeiros obtidas pelo cruzamento de Icatu com Catimor. Revista Ceres, 57:274-281.

Carvalho A, Monaco LC \& Fazuoli LC (1979) Melhoramento do Cafeeiro XL - Estudos de Progênies e Híbridos de Café Catuaí. Bragantia, 38:203-216.

Carvalho GR, Mendes, ANG, Bartholo, GF \& Amaral MA (2006) Avaliação e seleção de progênies resultantes do cruzamento de cultivares de café Catuaí com Mundo Novo. Ciência e Agrotecnologia, 30:844852.

Carvalho GR, Botelho CE, Bartholo GF, Pereira AA, Nogueira AA \& Carvalho AM de (2009) Comportamento de progênies $\mathrm{F}_{4}$ obtidas por cruzamento de 'Icatu' com 'Catimor'. Ciência e Agrotecnologia, 33:47-52.
Costa MJN, Zambolim L, Caixeta ET \& Pereira AA (2007) Resistência de progênies de café Catimor à ferrugem. Fitopatologia Brasileira, 32:121-130.

Correa LVT, Mendes ANG \& Bartholo GF (2006) Comportamento de progênies de cafeeiro Icatu. Ciência e Agrotecnologia,30:618-622.

Cruz CD (2006) Programa Genes: Biometria. Viçosa, Editora UFV. 382p.

Dell' Acqua R, Mantovani ES, Braghini MT, Oliveira CMG, Harakava R, Robaina AS, Petek MR \& Patrício FRA (2011) Variabilidade in vitro, in vivo e molecular de isolados de Cercospora coffeicola. Tropical Plant Pathology, 36:313-326.

Dias FP, Souza CAS, Mendes ANG, Carvalho SP de, Raso B de SM \& Botelho CE (2005) Caracterização de Progênies do Cafeeiro (Coffea arabica L.) Selecionados em Minas Gerais: II - Caracteres Relacionados à Produção. Revista Ceres, 52:85-100.

Fazuoli LC, Carvalho A, Costa WM da, Nery CL, Pereira CR \& Santiago M (1983) Avaliação de progênies e seleção no cafeeiro Icatu. Bragantia, 42:179-189.

Ferreira A, Cecon PR, Cruz CD; Ferrão, RG, Silva MF da, Fonseca AFA da; \& Ferrão MAG (2005) Seleção simultânea de Coffea canéfora por meio da combinação de análise de fatores e índices de seleção. Pesquisa Agropecuária Brasileira, 40:1189-1195.

Garcia Junior D, Pozza EA, Pozza AAA, Souza PE, Carvalho JG \& Balieiro AC (2003) Incidência e severidade da cercosporiose do cafeeiro em função do suprimento de potássio e cálcio em solução nutritiva. Fitopatologia Brasileira, 28:286-291.

Garçon CLP, Zambolim L, Mizubuti ESG, Vale FXR. \& Costa H (2004). Controle da ferrugem do cafeeiro com base no valor de severidade. Fitopatologia Brasileira, 29:486-491.

Hooker AL (1967) The genetics and expression of resistance in plants to rusts of the genus Puccinia. Annual Review of Phytopathology, 59:163-182.

Nogueira AM, Carvalho SP de, Bartholo GF \& Mendes ANG (2005) Avaliação da produtividade e vigor vegetativo de linhagens das cultivares Catuaí Vermelho e Catuaí Amarelo (Coffea arabica L.) plantadas individualmente e em diferentes combinações. Ciência e Agrotecnologia, 29:27-33.

Patrício FRA, Braghini MT \& Fazuoli, LC (2010) Resistência de plantas de Coffea arabica, C. canephora e híbridos interespecíficos à cercosporiose. Bragantia, 69:883-890.

Petek MR, Sera T, Altéia MZ, Azevedo JÁ, Triller C \& Fadelli S (2002) Análise de trilha entre caracteres agronômicos e dano de geada, em progênies derivadas do cruzamento "Vila Sarchi" x "Híbrido de Timor”. SBPN - Scientific Journal, 6:37-39.

Petek MR, Sera T, Sera GH, Fonseca IC de B \& Ito DS (2006) Seleção de progênies de Coffea arabica com resistência simultânea à mancha aureolada e à ferrugem alaranjada. Bragantia, 65:65-73.

Petek MR, Fazuoli LC, Mistro JC, Oliveira ACB \& Gallo PB (2007) Correlações e Análise de Trilha entre Reação à Cercosporiose e outras Variáveis em progênies de café arábica. In: $5^{\circ}$ Simpósio de Pesquisa Cafés do Brasil, Resumos expandidos. Emprapa café, Águas de Lindóia. CD-Room.

Pinto MF, Carvalho GR, Botelho CE, Gonçalves FMA, Rezende JC de \& Ferreira AD (2012b). Eficiência na seleção de progênies de cafeeiro avaliadas em Minas Gerais. Bragantia, 71:1-7.

Pinto MF, Carvalho GR, Botelho CE, Rezende JC, Andrade VT \& Carvalho JPF (2012a) Seleção de progênies de cafeeiro derivadas de Catuaí com Icatu e Híbrido de Timor. Coffee Science, 7:215-222.

Pozza AAA, Martinez HEP, Caixeta SL, Cardoso AA \& Zambolim L (2001) Influência da nutrição mineral na intensidade da mancha olho pardo em mudas de cafeeiro. Pesquisa Agropecuária Brasileira, 6:53-60. 
Reis PR \& Cunha RL (2010) Café arábica do plantio a colheita. Brasília, Embrapa Informação Tecnológica. 896p.

SAS Institute Inc. (2002) The Statiscal Analysis System (software). Version 8.2. Cary: SAS Institute Inc.

Santos F da S, Souza PE de, Pozza EA, Miranda JC, Carvalho EA, Fernandes LHM \& Pozza AAA (2008) Adubação orgânica, nutrição e progresso de cercosporiose e ferrugem do cafeeiro. Pesquisa Agropecuária Brasileira, 43:783-791.
Sera GH, Tumoru S, Ito DS, Azevedo JA de, Mata JS da, Doi DS \& Ribeiro Filho C (2007) Selection for Durable Resistance to Leaf Rust using Test- Crosses on IAPAR-59 and Tupi IAC 1669-33 cultivars of Coffea arabica Brazilian. Archives of Biology and Technology, 50: 565-570.

Sera GH, Sera T, Fonseca ICB, Ito DS, Del Grossi L, Shigueoka LH \& Kanayama FS (2010) Seleção para a resistência à ferrugem em progênies das cultivares de café IPR 99 e IPR 107. Bragantia, 69: 547-554. 